Ensino, Saúde e Ambiente - V9 (1), pp. 43-62, Abril, 2016.

\title{
EDUCAÇÃO A DISTÂNCIA PARA PROFESSORES DA REDE BÁSICA DE ENSINO: “COMO FAZER SAÚDE NA ESCOLA"?
}

\section{DISTANCE LEARNING FOR BASIC EDUCATION'S TEACHERS: “HOW TO HEALTH IN SCHOOL?"}

\section{Fernanda Roberta Daniel da Silva Portronieri}

Doutora em Educação em Ciências e Saúde-NUTES/UFRJ - Professora Substituta do Núcleo de Tecnologia Educacional para a Saúde - UFRJ - nutrisfer@yahoo.com.br Alexandre Brasil Carvalho da Fonseca

Doutor em Sociologia - USP - Professor do Núcleo de Tecnologia Educacional para a Saúde - UFRJ

\begin{abstract}
RESUMO:
Este trabalho traz os caminhos percorridos na construção colaborativa entre os pesquisadores e os professores da rede básica de ensino de um curso de educação à distância em saúde na escola. Trata-se de uma pesquisa participante em uma escola para construir, junto aos seus atores sociais, práticas educativas em saúde no ambiente escolar. Durante dezoito meses, desenvolveu-se o trabalho de campo com registros em diário além de 5 encontros específicos com professores e gestores desta, com mais de nove horas de gravação a respeito do tema saúde na escola. O processo de construção colaborativa do curso de educação à distância propiciou momentos de reflexão sobre os conceitos de saúde e de educação. A conclusão aponta que a busca ativa pela saúde necessita de uma formação que estimule a participação social nos processos regulatórios da saúde, uma formação política dos jovens para a cidadania. Extrapolou-se de uma definição estática para uma definição de saúde e de educação em saúde que busca complexificar suas várias vertentes de forma crítica e atuante. Contudo, as técnicas da construção colaborativa, enquanto pesquisa aberta ao diálogo com os sujeitos pesquisados, mostrou potencial pedagógico e de transformação abrindo novos caminhos para a educação em saúde na escola.
\end{abstract}

Palavras-chave: Educação em saúde na escola; Educação à sistância em saúde; Formação de professores.

\begin{abstract}
:
This research brings the paths taken in the collaborative construction among researchers and basic school teachers that work in a health at school distance learning course. This is a participatory research in a school that intends to build, with members of the school community, educational practices in health at school. Over eighteen months, the field work with daily records was developed besides 5 specific meetings with teachers and school managers, with more than nine hours of recording about the health issue at school. The collaborative process of building Distance Learning course propitiated moments of reflection on the concepts of health and education. The conclusion shows that the active search for health needs training that encourages social participation in the regulatory processes of health, a political training of young people for citizenship. The static concept was extrapolated by a definition of health and health education that seeks complexifying its various strands by critical and active way. However, the techniques of collaborative construction, while research, open to dialogue with the researched subjects showed a pedagogical and transformation potential opening new avenues for health education in school.
\end{abstract}

Key words: Health education in school; Distance learning in health; Teacher training. 


\section{INTRODUÇÃO}

Esse artigo é parte dos resultados de uma tese de doutorado que buscou identificar interfaces possíveis entre pesquisas em saúde e a educação em saúde na escola. A partir de uma pesquisa exploratória em 5 escolas do município do Rio de Janeiro, discutiu-se quais as possibilidades para uma educação em saúde eficaz e significativa dentro da rotina escolar. Um dos resultados que emergiram do trabalho de campo foi a necessidade de formação permanente para os professores da rede de ensino. Este trabalho traz os caminhos percorridos na construção colaborativa entre os pesquisadores e os professores da rede básica (pesquisados) de um curso à distância de educação em saúde na escola, fruto de uma pesquisa qualitativa de cunho etnográfico em uma das 5 escolas pesquisadas inicialmente.

Discutir o tema saúde dentro do contexto escolar não é uma tarefa fácil, principalmente pela característica transversal assumida pelos Parâmetros Curriculares Nacional - PCN - (BRASIL, 2000):

Com efeito, somente a participação das diferentes áreas, cada qual enfocando conhecimentos específicos à sua competência, pode garantir que os alunos construam uma visão ampla do que é saúde. Como contraponto, a transversalidade requer atenção para a consistência na concepção do tema, que não pode se diluir, levando a perder de vista os objetivos que se pretende atingir (PCN BRASIL, 2000).

A escola é um elemento chave no processo de Promoção da Saúde uma vez que os alunos passam grande parte do dia ali. Além disso, estabelecem uma primeira relação social diferente da família que possibilita conhecer novas culturas e pessoas. Cria-se, desta forma, um terreno fértil para atrelar ao conhecimento produzido, caminhos para se pensar o processo saúde-doença. No PCN, a educação é considerada um dos fatores mais significativos para a promoção da Saúde, sendo capaz de criar condições para os alunos desenvolverem plenamente suas potencialidades, adquirindo competências para cuidarem de si e se relacionar positivamente com o meio.

A educação em saúde é, portanto, uma das estratégias para a Promoção da Saúde dos indivíduos. Downie et al (1996) diz que é a interação entre a educação, a prevenção e a proteção em saúde que resultam na eficácia da promoção da saúde. A ideia proposta pelos autores acima, vai ao encontro do proposto na Carta de Ottawa (1986), dez anos antes, na ocasião da Primeira Conferência Internacional sobre Promoção da Saúde. Com o objetivo de atingir a "Saúde para Todos no ano 2000 e anos subsequentes", a carta de 


\section{Ensino, Saúde e Ambiente - V9 (1), pp. 43-62, Abril, 2016.}

intenções expressava uma resposta às crescentes expectativas por uma nova saúde pública, localizando as necessidades em saúde nos países industrializados. Definiu-se, na ocasião, a promoção da saúde como “o processo de capacitação da comunidade para atuar na melhoria de sua qualidade de vida, incluindo maior participação neste processo" (Carta de Ottawa, 1996). Além da educação em saúde, faz-se necessário a construção de políticas públicas saudáveis, a criação de ambientes favoráveis, o reforço da ação comunitária e o desenvolvimento das habilidades pessoais.

\footnotetext{
"A promoção da saúde apoia o desenvolvimento pessoal e social através da divulgação e informação, educação para a saúde e intensificação das habilidades vitais. (...) É essencial capacitar as pessoas para aprender durante toda a vida, preparando-as para as diversas fases da existência, o que inclui o enfrentamento das doenças crônicas e causas externas. Esta tarefa deve ser realizada nas escolas, nos lares, nos locais de trabalho e em outros espaços comunitários" (Carta de Ottawa, 1986; p. 3- grifo nosso).
}

O conceito de educação em saúde como parte da promoção em saúde também é descrito por Schall e Struchner (1999), que consideram a promoção como um processo mais amplo que abrange a participação de toda a comunidade no contexto da vida cotidiana e não se restringe apenas ao risco de adoecer. Tal concepção de educação em saúde está vinculada a um conceito de saúde ampliado, considerado como um estado positivo e dinâmico na busca do bem estar físico, mental, ambiental, pessoal, emocional, sócio-ecológico. A educação em saúde ampliada, portanto, inclui políticas públicas, criação de ambientes propícios e orientação dos serviços de saúde para além dos tratamentos clínicos e curativos, práticas educativas libertadoras que visem também a construção da cidadania.

No contexto escolar, a promoção da saúde deve utilizar todas as oportunidades educativas formais e informais, proporcionando a reflexão e a análise crítica da informação (Ippolito-Shepherd; 2002). A educação em saúde, portanto, é uma peça fundamental quando se pensa em promover saúde. Sem uma efetiva educação que permita aos alunos terem consciência e autonomia das suas escolhas em relação à saúde, é quase impossível promovê-la. A Organização Panamericana de Saúde (OPAS) (1998) ainda define a escola como um local de excelência, pois os professores reconhecem a importância da saúde de seus alunos como um dos aspectos fundamentais para a sua qualidade de vida e seus processos de crescimento, desenvolvimento e aprendizagem. A dinâmica curricular deve ser planejada de forma que vá ao encontro das necessidades das crianças e dos jovens, atendendo seu percurso de desenvolvimento e incluindo todos os atores do processo ensino-aprendizagem: pais, professores, alunos e a comunidade 


\section{Ensino, Saúde e Ambiente - V9 (1), pp. 43-62, Abril, 2016.}

em geral. A educação em saúde nas dinâmicas curriculares das escolas só será útil se objetivar pela autonomia dos educandos e pela participação ativa de crianças e jovens na construção das atividades educativas e assim, do saber. Dessa forma, eles terão o conhecimento de modos alternativos de lidar com a ansiedade, com o stress, com os relacionamentos, e sem ter que recorrer a comportamentos inadequados como o consumo de substâncias aditivas, violência, sexualidade de risco, etc. (Rodrigues et al, 2007).

Vários trabalhos apontam o papel chave dos professores para trabalhar os temas relacionados à saúde na escola (Focesis, 1990; Mota, 2011; Fernandes et al, 2005; Nonose e Braga, 2008) seja pela linguagem mais propícia aos jovens (em relação aos profissionais de saúde), pela afinidade que os mesmos têm com os alunos ou pelo tempo prolongado em que estão com os mesmos. De acordo com o Ministério da Educação (MEC, 2001), no modelo de escola promotora de saúde, os professores assumem um papel especial da educação em saúde. Portronieri e Fonseca (2012), a partir de uma etnografia na escola, relatam em seus resultados que os professores influenciam de forma significativa a opinião dos alunos e consequentemente suas atitudes. Diferente do que os professores imaginavam, eles representam um "ídolo", cuja opinião é importante ser ouvida e seguida, mesmo em meio às adversidades do contexto escolar ou até diante das atitudes peculiares à faixa etária dos adolescentes, que normalmente são de aparente resistência e contrariedades.

Mas como os professores se sentem frente a essa demanda de educação em saúde na escola? Sentem-se preparados para abordar os temas? Já existem vários estudos relatando a necessidade de formação tanto no currículo básico de sua graduação, quanto complementar para que o professor possa abordar os mais variados temas em saúde na escola (Iervolino e Pelicioni, 2005; Fernandes et al, 2005; Costa et al, 2011; Gustavo e Galieta, 2014; Venturini et al, 2013; Venturini et al, 2014). Casemiro et al (2014) em uma ampla revisão bibliográfica sobre a promoção de saúde na escola, concluem que salta aos olhos a recorrência, nos artigos analisados, de diversos depoimentos e recomendações relacionados à formação em saúde escolar e que o professor é o profissional mais citado neste aspecto. 


\section{Ensino, Saúde e Ambiente - V9 (1), pp. 43-62, Abril, 2016.}

\section{BREVE HISTÓRICO DO ENSINO A DISTÂNCIA}

A educação à distância surgiu ao final do século XIX nos EUA e na Europa, com a finalidade de atender a uma população com dificuldades de frequentar cursos regulares e presenciais (Reali, Tancredi e Mizukami; 2008). Embora já tenha sido vista como uma solução paliativa, rejeitada pela maioria dos professores das grandes universidades públicas e denunciada por movimentos de estudantes e professores, como uma concessão à oferta de ensino de baixa qualidade, a EaD aparece agora como caminho não apenas para a ampliação rápida do acesso ao ensino superior, mas também, e principalmente, como uma nova solução de melhoria da qualidade desse ensino, no sentido de adequá-lo às exigências e características do século XXI (Reali, Tancredi e Mizukami, 2008; Belloni, 2012).

Dentre as diversas modalidades de educação à distância, temos a educação online, que pode favorecer o desenvolvimento do pensamento, a autonomia, o compartilhamento de saberes e a aprendizagem. Em particular, a internet tem se configurado como um amplo campo de busca compreendendo informações, documentos, textos, artigos, imagens, músicas, vídeos. Permite a comunicação rápida entre as pessoas, em tempo real ou não. Possibilita, por suas características, a formação de comunidades de aprendizagens formadas por pessoas das mais diversas culturas e procedências (Reali, Tancredi e Mizukami; 2008). No entanto, um sério problema que se observa nos cursos que ocorrem via internet é a tendência de transferir uma concepção de ensino e aprendizagem presencial para os computadores: a transmissão do conhecimento. Para que a educação online possa atingir seu potencial máximo, é importante que sejam adotadas concepções e práticas de ensino e aprendizagem que considerem os envolvidos como aprendizes ativos e responsáveis pelo próprio desenvolvimento, o qual se dá ao longo da vida e em diferentes contextos, não apenas nas escolas (Reali, Tancredi e Mizukami; 2008).

Entendemos que o processo educativo deve se dar a partir da "problematização", como nos diz Paulo Freire (2005). Deve ser planejado e estruturado junto à população, visando a efetividade da construção do conhecimento, conferindo autonomia ao sujeito e permitindo que o mesmo tenha condições de decidir por si, com liberdade. A educação em saúde, seguindo essa lógica, ao conferir maior autonomia aos sujeitos atinge seu objetivo principal que é proporcionar melhores condições de vida aos indivíduos. Se os conhecimentos nas mais diversas áreas da saúde não tiverem calcados 


\section{Ensino, Saúde e Ambiente - V9 (1), pp. 43-62, Abril, 2016.}

com a realidade sociocultural do indivíduo, podem não surtir o efeito desejado e não promover saúde.

A educação quando se pauta no reconhecimento da importância de se identificar e responder aos aspectos afetivos e comportamentais, possibilita a participação ativa dos educandos nas ações de saúde, de forma a estabelecer o desenvolvimento contínuo de habilidades e técnicas para o autocuidado (Souza, 2009). O educador não pode assumir a posição de detentor do conhecimento que se transmitirá de forma passiva ao educando, subestimando àquele já existente no mesmo, sem problematizar e torná-lo ativo no processo de aprendizagem. Quando a prática educativa é dominante e disciplinadora, não favorece a emancipação e autonomia do sujeito, podendo acarretar em resistências ao saber outorgado.

Quando se problematiza e dialoga com os atores envolvidos, há uma valorização do saber do educando, do seu contexto sociocultural, o que propicia uma construção do conhecimento tanto pelo educador quanto pelo educando, além de despertar nesse último a criticidade, e não o tornando um mero depósito de novos conhecimentos, passivo ao processo de aprendizagem (Paulo Freire, 2005). Esta visão rompe com o modelo clássico da posição do educador, uma vez que o mesmo também é educado, e que o educando, com sua participação, também é educador.

A prática educativa passa a ser, dessa forma, um espaço de reflexão e ação sobre a realidade em que se vive e o conhecimento da realidade, por sua vez, é necessário para a tomada decisão consciente em relação a sua saúde. O modelo participativo da prática educativa em saúde possui maior comprometimento para a melhoria das condições de vida da população, reconhece e valoriza o saber popular, estimula a reflexão, a crítica e a parceria entre educador e educando (Sabóia, 2003).

Moran (2003) apud Reali, Tancredi e Mizukami (2008) diz que, no entanto, alguns cursos online ainda reproduzem as mesmas problemáticas do ensino presencial, simplificando o processo pedagógico. Há pouca preocupação com a construção do conhecimento, por estarem mais preocupados com o lucro, além de continuarem centrados no conteúdo e na transmissão da informação para os alunos. É a educação tradicional que prevalece na grande maioria dos cursos, como corroboram autores como Nova e Alves (2003); Ramal (2003); Santos (2003) apud (Reali, Tancredi e Mizukami; 2008).

Contudo, objetivou-se construir, junto aos professores da rede básica de ensino, um curso à distância de educação em saúde na escola que levasse em consideração o que os 


\section{Ensino, Saúde e Ambiente - V9 (1), pp. 43-62, Abril, 2016.}

professores compreendiam por saúde, como eram realizadas as atividades de educação em saúde com os alunos; quais as percepções a respeito da saúde dos alunos; quais as lacunas que pretendiam preencher através deste conhecimento compartilhado, tanto no decorrer da construção do curso, quanto durante o mesmo.

\section{METODOLOGIA}

Como citado acima, esse artigo traz parte de uma pesquisa mais ampla de doutorado. A partir de uma pesquisa exploratória em 5 escolas diferentes no município do Rio de Janeiro (2 estaduais, 2 municipais, 1 particular) buscou-se estabelecer interfaces entre a pesquisa em saúde na escola e a educação em saúde. A pesquisa foi qualitativa, com entrevistas semiestruturadas, grupos focais e observação participante com anotações em diário de campo. Ao total, participaram 33 professores das entrevistas e grupos focais. A análise dos dados da fase exploratória se deu através da Análise dos Quadros Sociais de Erving Goffman (2012). O método de análise busca o olhar das interações sociais, contextualizando cada fala significativa de acordo com a vivência e olhar do sujeito. Para Goffman (2012), a unidade básica de análise deve incorporar o contexto, as barreiras espaciais e temporais que o circunscrevem e as regulações ou especificações da conduta por ela prescrita. Através das análises das interações sociais, busca as impressões da sociedade nos indivíduos e suas consequências para a sociedade. É através do "enquadramento" que o sujeito faz da situação que as interações e as próprias falas ganham significado.

Um dos resultados desta parte da pesquisa foi a necessidade sentida pelos professores de formação permanente em saúde na escola, conforme as falas abaixo:

"Não, meu filho, eu não sei por que eu não sou especialista, quem tem que saber é o especialista." Resposta relatada por uma professora a um aluno sobre os resultados dos exames de sangue realizados durante o uma pesquisa em saúde na escola. - GRUPO FOCAL 1 - ESCOLA MUNICIPAL - ZONA SUL DO RIO DE JANEIRO.

"Porque VÁRIAS dúvidas surgiram e eu não soube responder a nenhuma, entendeu?" Se referindo às questões que surgiram após a pesquisa em saúde na escola, relacionadas aos resultados de exames de sangue - GRUPO FOCAL 1 - ESCOLA MUNICIPAL - ZONA SUL DO RIO DE JANEIRO.

"Para elaborar algo mais certinho, mais estruturado, a gente teria a necessidade de ter um especialista na escola, junto, fazendo junto, criando junto ou até a disponibilidade da gente fazer algum curso de especialização que tratasse esses temas da saúde, entendeu?" - GRUPO FOCAL 1 - ESCOLA MUNICIPAL - ZONA SUL DO RIO DE JANEIRO. 


\section{Ensino, Saúde e Ambiente - V9 (1), pp. 43-62, Abril, 2016.}

"E uma coisa assim, eu penso sempre, porque na sala de aula você ta vendo os alunos tão doentes, né? Assim; crianças com depressões, o sedentarismo deles, o tempo que eles ficam no celular; meu Deus! Faz falta pra gente saber como tratar essas coisas na escola, como falar, como atrelar sem ser só rapidinho ali na aula quando eles perguntam. GRUPO FOCAL 2 - ESCOLA ESTADUAL - ZONA OESTE DO RIO DE JANEIRO.

Uma vez sabido, conforme dito acima, que os professores constituem-se um duplo elemento-chave, pois tanto são indicados como aqueles que facilitam a entrada das pesquisas nas escolas, como aqueles que têm maiores afinidades com os alunos e por isso são potencialmente capazes de mediar o conhecimento técnico sobre saúde com a facilidade de transitar na linguagem dos jovens, apontamos o empoderamento dos professores como uma importante interface entre a pesquisa em saúde e a educação em saúde na escola. Seja através de cursos, de capacitações, de estar aberto às dúvidas que surgem referentes às pesquisas realizadas e como elas podem refletir em educação na escola, seja na escuta atenciosa das demandas locais. Compartilhar saberes, dialogar com atores envolvidos e construir um novo saber que possa viabilizar a educação em saúde na escola.

Com essa dificuldade assinalada pelos professores, surgiu a ideia de se construir junto aos mesmos um curso de educação à distância (EAD) sobre saúde na escola. A característica "à distância” também respondeu às necessidades dos professores, diante da falta de tempo para realizar um curso presencial.

Esse artigo discute o segundo momento da pesquisa: a imersão em uma das escolas para a construção colaborativa de um curso de aperfeiçoamento em saúde para os professores. Trata-se de uma pesquisa participante em uma escola estadual da Zona Oeste do Rio de Janeiro. A partir dos resultados de uma pesquisa exploratória em cinco escolas do Rio de Janeiro, foi realizada uma imersão em uma das escolas para construir, junto aos seus atores sociais, práticas educativas em saúde no ambiente escolar.

Durante dezoito meses, a pesquisadora desenvolveu o trabalho de campo na escola. Houve inicialmente a participação em alguns projetos já em andamento, tais como o projeto da horta escolar e de sustentabilidade. A recepção pelos gestores da escola se deu de forma amistosa e consolidou-se num terreno fértil para também realizar oficinas sobre saúde, alimentação e ambiente junto aos atores sociais da escola. Todos os momentos da escola foram registrados em diário de campo e analisados para a construção de um curso de educação a distância para os professores que guardasse relação com os problemas identificados ali, as necessidades da comunidade e do entorno escolar e a saúde dos alunos. 
No decorrer desse processo, foram realizados 5 encontros com professores e gestores desta escola (primeiro encontro: 15 professores; segundo encontro: 6 professores; terceiro encontro: 8 professores; quarto encontro: 10 professores), totalizando mais de nove horas de discussão a respeito do tema saúde na escola. Os encontros foram gravados em meio digital e posteriormente transcritos. A pesquisa possui aprovação no Comitê de ética e todos os participantes somente iniciaram a participação no processo após lerem, entenderem e assinarem o Termo de Consentimento Livre e Esclarecido.

\section{RESULTADOS E DISCUSSÃO: CAMINHOS DA CONSTRUÇÃO COLABORATIVA DO CURSO DE EDUCAÇÃO EM SAÚDE NA ESCOLA}

Participaram da construção colaborativa do curso ao todo 15 profissionais da escola (dentre professores, gestores e funcionários). O quadro a seguir resume o perfil geral dos participantes:

\begin{tabular}{|l|l|l|l|l|l|}
\hline Participante & Profissão / Atuação & $\begin{array}{l}\text { Tempo de } \\
\text { atuação na } \\
\text { escola }\end{array}$ & $\begin{array}{l}\text { Idade } \\
\text { (anos) }\end{array}$ & Sexo & $\begin{array}{l}\text { Tempo de } \\
\text { formação }\end{array}$ \\
\hline 1 & Diretora & 8 anos & 45 & feminino & 20 anos \\
\hline 2 & Vice-diretora & 12 anos & 48 & feminino & 25 anos \\
\hline 4 & Professora de Sociologia & $\begin{array}{l}\text { Inferior a } 1 \\
\text { ano }\end{array}$ & 28 & feminino & 5 anos \\
\hline 5 & $\begin{array}{l}\text { Professor de Educação } \\
\text { física /Coordenador }\end{array}$ & 8 anos & 42 & masculino & 18 anos \\
\hline 6 & Professora de Geografia & 7 anos & 39 & feminino & 20 anos \\
\hline 7 & Professora de Geografia & 9 anos & 41 & feminino & 19 anos \\
\hline 8 & Professora de Biologia & 2 anos & 35 & feminino & 12 anos \\
\hline 9 & Professora de Biologia & 1 ano & 27 & feminino & 5 anos \\
\hline 10 & Pedagoga & 16 anos & 41 & feminino & 11 anos \\
\hline 11 & Bibliotecária / Pedagoga & 4 anos & 39 & feminino & 16 anos \\
\hline 12 & Professora de Português & 9 anos & 42 & feminino & 20 anos \\
\hline 13 & Professor de História & 7 anos & 44 & masculino & 21 anos \\
\hline 14 & Professora de Artes & 1 ano & 27 anos & feminino & 5 anos \\
\hline 15 & Professora de Filosofia & $\begin{array}{l}\text { Menos de } 1 \\
\text { ano }\end{array}$ & 28 anos & feminino & 3 anos \\
\hline & Professora de Português & 16 anos & 37 anos & feminino & 14 anos \\
\hline
\end{tabular}




\section{Ensino, Saúde e Ambiente - V9 (1), pp. 43-62, Abril, 2016.}

A cada encontro os áudios foram transcritos e analisados para serem levados aos professores no próximo encontro, a fim de validar a análise e a construção da grade do curso de educação em saúde na escola junto aos professores participantes. Após a análise da transcrição do primeiro encontro, associada aos registros em diário de campo da pesquisa participante na escola (durante os doze meses - até então), chegou-se a cinco categorias a serem abordadas durante o curso. Essas categorias foram escolhidas por se destacarem durante o primeiro encontro e por conseguirem abarcar outros temas menores em sua discussão. Além das categorias, destacou-se o que nós chamamos de "eixos", que foram temas bastante reincidentes durante a pesquisa e os encontros e que definimos que deveriam estar presentes em todos os módulos do curso (que se derivaram das categorias).

Após análise das falas, chegou-se às seis categorias: saúde para além de doença; hábitos de vida, saúde e ambiente; saúde e alimentação, estratégias de educação em saúde na escola: a prática, o Programa Nacional de Alimentação Escolar (PNAE) como caminho para a Educação em Saúde na Escola.

As seis categorias definiram a primeira estrutura do curso. Além das categorias, definimos dois eixos que apareceram em todas as categorias: "O Jovem como protagonista" e "Colocar a mão na massa", pois, havia na fala dos professores a preocupação em atrelar os conhecimentos construídos no curso à distância à prática escolar e que o processo educativo conferisse autonomia aos alunos diante das escolhas relacionadas à saúde. Algumas dessas falas estão abaixo:

\footnotetext{
"Assim, a gente tem que trabalhar pensando na criança. Criança quando você faz ela manipular, participar da produção daquele alimento, ela acaba se sentindo parte dele e quer experimentar e tudo mais, eu acho que tinha que ser muito por aí. Além da gente estar fazendo essa questão teórica, botar também algumas questões prática, também, colocar a "mão na massa", pra levar as turmas, fazer com as turmas... uma ação completa." REUNIÃO DE CONSTRUÇÃO DO CURSO DE EAD ENCONTRO 1 - DIRETORA.
}

"A gente fez aqui uma grande salada de frutas (...) Eles participaram de todo processo. E aí você via realmente isso que se falou, do envolvimento, da afetividade que vira efetividade. Do botar a mão na massa! Você se sente realmente comprometido, né? Mais do que envolvido somente." REUNIÃO DE CONSTRUÇÃO DO CURSO DE EAD - ENCONTRO 1 - VICE DIRETORA.

"Hoje as crianças estão muito ligadas pela mídia, né, estão muito ligada a comer o que a mídia diz (...) Algumas doenças que a gente sabe, que tem o alimento como emergente. $\mathrm{O}$ sal, o açúcar em excesso, então isso tudo a gente vai trabalhando com eles. Então, quando a gente leva eles para a oficina de agroecologia, a gente também tem essa interação deles com o plantio, e também com o transformar o 
alimento.” REUNIÃO DE CONSTRUÇÃO DO CURSO DE EAD - ENCONTRO 1 - PROFESSORA A.

A segunda reunião objetivou validar a transcrição realizada e a pré-análise em categorias e eixos temáticos. Além disso, discutiu-se os temas que se encaixariam nas categorias, levando-se em consideração o tempo que o curso teria (quatro meses - num total de 180 horas) e os métodos utilizados no curso. As falas abaixo retratam a validação pelos participantes.

"Eu achei essa estrutura maravilhosa". PROFESSORA A - REUNIÃO 2

"Os módulos abarcam todo o material que foi discutido." PROFESSOR B - REUNIÃO 2

"Você captou exatamente tudo o que dissemos e o conteúdo vai se permeando, não fica uma coisa bem estanque." VICE DIRETORA - REUNIÃO 2

"Eu acho que essa parte, a forma como você... foi ali conseguiu costurar tudo. Eu achei fantástica" VICE DIRETORA - REUNIÃO 2

Sobre a estrutura do curso, os professores sugeriram fóruns de discussão, leitura de textos com sequente elaboração de novos textos (resenhas, críticas, etc), individual ou coletivamente.

"Como ideia, assim, da construção participativa, pensei em metodologias através de bibliografia. Em que os alunos leem artigos e depois escrevem alguma coisa. E depois discute. Aula também com relato de prática. Um relato de prática assim, dentro do tema sugerido; dar algum vídeo em aula, e que leva para fórum; para discussão. Acho interessante isso." PROFESSORA C - REUNIÃO 2.

"Fórum é muito legal, você debate com pessoas do Brasil inteiro sobre um tema." VICE-DIRETORA REUNIÃO 2.

Após essa fase de aprovação e corroboração do esquema inicial de curso construído, no terceiro encontro foi apresentada mais uma vez uma síntese das análises das falas e da estrutura do curso construída até ali. A partir da corroboração dessa estrutura, iniciamos a construção menor, em temas, módulos e aulas. Os professores falaram das principais dúvidas e dificuldades em se abordar o tema na escola. No início da pesquisa, partimos do pressuposto de que a carência em relação à prática de educação em saúde na escola fosse de conteúdos sobre a saúde ou ao processo saúde/doença. No entanto, no decorrer do processo, notamos que a necessidade era saber como fazer educação em saúde na escola: 


\section{Ensino, Saúde e Ambiente - V9 (1), pp. 43-62, Abril, 2016.}

"Eu fico pensando assim: os malefícios do fumo, da bebida, até de uma comida inadequada, por mais que todo mundo não saiba a fundo, a gente sabe minimamente. Tem internet aí que ajuda a confirmar as informações e tal... Então não é o malefício do fumo, por exemplo, né. Temas como esses (questão saúde/ doença) começam a aparecer e ai o professor e a escola não sabem o que fazer. Como fazer saúde na escola" REUNIÃO DE CONSTRUÇÃO DO CURSO DE EAD - ENCONTRO 2 PROFESSOR G

"Eu acho que um dos grandes problemas que nós enfrentamos são as estratégias, por quê? Porque às vezes não é que o professor se feche que ele não quer fazer, ele não sabe como fazer... É falando como professor: Eu quero fazer e eu não sei como, como e onde eu vou inserir isso, dentro do meu conteúdo programático." REUNIÃO DE CONSTRUÇÃO DO CURSO DE EAD - ENCONTRO 2 - VICE DIRETORA

"Eu acho que esse é... onde emperra... quando a gente fala da interdisciplinaridade, da transversalidade, porque ele (o professor) não sabe... a verdade é essa; a gente não sabe como inserir esse tema, a gente sempre esbarra nisso, o que isso tem a ver? Isso não tem nada a ver comigo. Se a gente vai falar, por exemplo, esse assunto de DST se tiver que falar sobre esse tema, a primeira coisa que se fala é "ah, esse tema é só de biologia". Não necessariamente vai ser assim, tema de biologia." REUNIÃO DE CONSTRUÇÃO DO CURSO DE EAD - ENCONTRO 2 - PROFESSORA F

A partir dessa necessidade apontada em se estudar estratégias de educação em saúde na escola, refinou-se a estrutura para um curso que discutisse práticas educativas em saúde, métodos de trabalhar temas em saúde, sempre atrelando conteúdos teóricos que dessem subsídios para a compreensão do processo educativo em saúde às atividades práticas a serem aplicadas na escola, em diversos contextos. Algumas atividades foram pensadas ainda nesse processo de construção da grade do curso, mas deixou-se espaços nos módulos para que outras atividades possam ser construídas também ao longo do processo, de forma espontânea e de acordo com as necessidades de cada professor. Dessa forma, os temas relacionados ao processo saúde e doença, tais como depressão, uso de anabolizantes, diabetes, obesidade, transtornos alimentares, fumo, bebidas alcoólicas, dentre tantos outros que surgiram, acabaram ficando para um segundo foco, como sugestão de links e leituras de apoio de fonte confiáveis para que os professores pudessem consultar quando fossem fazer atividades mais direcionadas a algum conteúdo específico de saúde e ou doença.

Ao refletir sobre educação em saúde na escola durante esse processo, os professores concluíram que abordar tais temas é importante na formação do jovem, mas o principal obstáculo não está na definição das patologias ou nas formas de prevenção, e sim em como falar de saúde de forma integral e contínua na escola, perpassando o currículo e as disciplinas, as aulas e os demais momentos. Buscar informações sobre as doenças é relativamente fácil nos dias atuais com a disponibilidade de pesquisa através de internet, principalmente com o advento dos smartphones. Mas, como ultrapassar os 


\section{Ensino, Saúde e Ambiente - V9 (1), pp. 43-62, Abril, 2016.}

limites da demanda de conteúdo, das aulas, das atividades curriculares? Como a educação em saúde pode se dar de maneira transdisciplinar? Esses foram os principais questionamentos e obstáculos que os professores associaram a não realização de atividades educativas em saúde ou a sua realização de forma pontual.

No quarto encontro, avaliou-se o cronograma do curso mais "costurado" e propôsse um referencial bibliográfico, atividades e trabalhos; além das bases conceituais e as ferramentas. No quinto e último encontro, o cronograma foi fechado e o título definido: “Curso de Aperfeiçoamento em Educação em Saúde na Escola: A saúde está na mesa".

A partir daí, o curso foi submetido para avaliação no site da Pró-reitora de Extensão da universidade de origem dos pesquisadores, como um curso de educação à distância, de nível de Aperfeiçoamento, com 180 horas, voltado para professores da Rede Básica de Ensino. O curso foi submetido em 04 de fevereiro de 2015 e foi aprovado em 17 de abril de 2015. Após divulgação para os professores desta escola, o curso teve início em junho de 2015.

Numa segunda etapa (após as reuniões) os professores foram capacitados no uso da informática e da internet. E, na terceira etapa (em andamento), a aplicação do curso. Numa plataforma específica acontecem os contatos semanais entre os professores responsáveis por meio de correspondências eletrônicas, fóruns de discussão, espaços para atividades, videoconferências, etc. Nesses contatos, tem se desenvolvido um conjunto de experiências de ensino e aprendizagem sobre saúde na escola, com relatos de experiência, aplicação de atividades sugeridas pelos responsáveis pelo curso e pelos próprios professores da rede básica de ensino.

Foram abertas vinte vagas ao total; quinze professores se inscreveram no curso. Destes, sete participaram do processo de construção. Todos estão ativos durante esse primeiro mês do curso. Há professores de biologia, informática, geografia, matemática, educação física, língua portuguesa, biologia, além da diretora da escola, da coordenadora pedagógica e a vice-diretora. Essa pluralidade de professores contribuiu significativamente para que as discussões fossem transdisciplinares e culminasse na construção de um curso que levasse em consideração os diferentes contextos nos quais se pode fazer educação em saúde na escola. No entanto, a análise a respeito do curso em si não é objetivo deste artigo, que buscou trazer a rica experiência da construção colaborativa no processo de aprendizagem tanto dos pesquisadores quanto dos pesquisados. 


\section{Ensino, Saúde e Ambiente - V9 (1), pp. 43-62, Abril, 2016.}

Um resultado importante foi que durante o processo de construção, os professores puderam refletir a respeito do que entendem por saúde e a partir da reflexão, apontar meios de se fazer educação em saúde na escola.

As falas dos professores ao fazer a pergunta inicial "O que é importante num curso para se trabalhar a saúde dos jovens na escola?" no primeiro encontro, mostraram que o conceito de saúde está além da ausência de doença, de acordo com o proposto pela Organização Mundial da Saúde:

"Começamos com o hábito. Que horas você acorda, que alimento você come... porque o jovem, hoje, ele passa a noite inteira acordado e vai comer no outro dia, então com isso daí já começa a formação de hábito que vai desenhando a saúde dele". REUNIÃO DE CONSTRUÇÃO DO CURSO DE EAD ENCONTRO 1 - PROFESSORA C.

"Eu já vi uma pessoa conversando com a outra do lado pelo whatsap. Do lado! Às vezes sai a família, ta cada um com um (celular) na mesa, e ninguém se conversa. Eu já vi isso em um restaurante. Quatro pessoas. Era o pai, o avô, com duas crianças. Tá cada vez mais difícil compreender essa sociedade.... é doentio!” REUNIÃO DE CONSTRUÇÃO DO CURSO DE EAD - ENCONTRO 1 - DIRETORA.

"Eu vejo a saúde, não só como ausência de doença, mas como um bem viver. Eu associo muito à saúde, a questão de... como...como você lida com o seu tempo livre, por exemplo." REUNIÃO DE CONSTRUÇÃO DO CURSO DE EAD - ENCONTRO 1 - PROFESSORA A.

"O que que está acontecendo com esse lençol freático aqui do nosso entorno? O que que tá acontecendo nesta parte lagunar aqui das Bacias de Jacarepaguá? Eu acho assim que a parte de mobilidade urbana versus o que que a gente ta fazendo com esse local que a gente vive, influencia muito na nossa saúde.” REUNIÃO DE CONSTRUÇÃO DO CURSO DE EAD - ENCONTRO 1 VICE DIRETORA.

"Porque a agroecologia, a proposta de agroecologia é uma agricultura de base ecológica, onde a gente trabalha a vertente da alimentação saudável, mas também trabalha agrotóxico, efeitos na saúde, é.. é.. preservação de matas ciliais, preservação de lençol freático" REUNIÃO DE CONSTRUÇÃO DO CURSO DE EAD - ENCONTRO 1 - PROFESSORA A.

Nota-se que os temas que os professores relacionaram à saúde envolvem desde a ausência de doença, passando pela alimentação, condições ambientais, hábitos de vida, aproveitamento do tempo. No entanto, no decorrer da pesquisa, os sujeitos pesquisados acrescentaram às definições de saúde, uma busca ativa pela mesma, seja através do processo reflexivo crítico, seja por meio de redes de amparo à saúde, seja no posicionamento político diante das contrariedades de um sistema que se almeja mudar para melhor atender às demandas da comunidade.

"O jovem às vezes não consegue entender, né, que aquilo é uma porta de entrada para uma porta de saída... não é para ele ficar amarrado àquela condicionalidade que ele tem, da saúde ou da vida. $\mathrm{O}$ 
conhecimento, a reflexão que se faz em torno desta questão de saúde, né? É fundamental ta amadurecendo isso na cabeça deles, porque eles não têm esse foco. O foco deles é outro, a gente tem puxar porque... eles desviam o foco. Então a gente tem que estar sempre fazendo essa reflexão de que é possível haver mudanças. REUNIÃO DE CONSTRUÇÃO DO CURSO DE EAD - ENCONTRO 3 - PROFESSORA G.

“A gente é formiguinha. Como é que a gente vai matar o dinossauro?"(fala reprodutiva do aluno) Eu falei assim: "Então não pensa no dinossauro. Pensa no elefante! Sei lá... na anta. Né? Imagina, um monte de formiga vai incomodar a anta, um monte de anta vai incomodar o elefante, e o elefante vai incomodar o dinossauro. (Risos) Entendeu? Mas é possível, né? Aí ele ficou parado. "É verdade, professora!" Então, quer dizer, de repente, tentando fazer diferença num pequeno núcleo, foi isso que eu tentei mostrar pra eles, né? (...) Como a gente atinge o aluno e como esse aluno multiplica, não é? É, entender que você faz diferença no processo, né? Que não vem só de cima pra baixo, que é possível, né, uma mudança de baixo pra cima. E na saúde isso também acontece. REUNIÃO DE CONSTRUÇÃO DO CURSO DE EAD - ENCONTRO 3 - PROFESSORA E.

"Mas ela (a mudança) sempre foi de cima pra baixo, né? Continua sendo, né? Mas os... as poucas mudanças que ocorreram, ocorreram porque teve uma minoria que em algum momento se manifestou, né? Se incomodou... que não se acomodou. Que se manifestou, que brigou, né? Saber que pode, né?"REUNIÃO DE CONSTRUÇÃO DO CURSO DE EAD - ENCONTRO 3 - VICE DIRETORA.

A percepção da importância de discutir os temas relacionados não somente à saúde, mas à educação como um todo e aos problemas e intercorrências do cotidiano escolar foi refletida na fala abaixo:

"Eu fico muito feliz que o curso tenha dado certo e que construímos mais um espaço que efetivamente destinaremos um tempo para discutir questões tão importantes. Esse espaço de discussão que nós iniciamos na escola pessoalmente foi fundamental para escutarmos e refletirmos sobre questões que às vezes ficam no lugar do senso comum. Falar sobre essas questões junto com outros colegas que passam pelas mesmas coisas, nos ajuda a redesenhar nossos pensamentos." DEPOIMENTO DA VICE DIRETORA AO SABER DA APROVAÇÃO DO CURSO.

Paulo Freire (1996) diz que não há ensino sem pesquisa e nem pesquisa sem ensino. A docência-discência (como faces da mesma moeda) e a pesquisa não se dicotomizam. "Ensinar, aprender e pesquisar lidam com esses dois momentos do ciclo gnosiológico: o em que se ensina e se aprende o conhecimento já existente e o em que se trabalha a produção do conhecimento ainda não existente" (PAULO FREIRE, 1996, P.15). A experiência da construção colaborativa de um curso que visa a educação problematizadora em saúde na escola proporcionou experimentar os dois lados da mesma moeda, aprender e ensinar e possibilitou que novos horizontes se abrissem para pensar a educação em saúde na escola, ainda durante a fase da pesquisa. 


\section{Ensino, Saúde e Ambiente - V9 (1), pp. 43-62, Abril, 2016.}

Esse tempo-espaço da pesquisa na escola também propiciou um olhar diferenciado sobre o Programa Nacional de Alimentação Escolar como um caminho para a educação em saúde.

“Agora eu estou pensando aqui, porque a gente já tem projetos na escola de agroecologia, de aproveitamento da luz solar, de reutilização do óleo de cozinha como combustível... com a construção do nosso refeitório, isso fica mais amarradinho. A gente pode trabalhar a saúde a partir da alimentação, mas vai acabar passando por tudo isso... o ambiente, quando a gente fala das formas de produção, dos solos, da água... A gente fala do aproveitamento integral do alimento, dos nutrientes, da biologia da coisa mesmo. Dá pra começar a integrar todos esses projetos. Falar de segurança alimentar e nutricional, de higiene... da agricultura familiar. É todo esse gancho que está amarrado na alimentação aqui na escola." REUNIÃO DE CONSTRUÇÃO DO CURSO DE EAD - ENCONTRO 2 - DIRETORA.

Glanz et al (2008) diz que as práticas em saúde e em educação são tanto para compreender o comportamento em saúde quanto para transformar o conhecimento sobre o comportamento em estratégias eficazes para a melhoria da saúde. Da mesma forma, a pesquisa em educação em saúde e em comportamento de saúde são julgados de acordo com suas contribuições para a melhoria da saúde das populações. Embora a pesquisa comportamental básica é importante para o desenvolvimento de teorias, devemos, ao fim, testar nossas teorias de forma interativa em contextos do mundo real. Quando fazemos isso, a teoria, a pesquisa e a prática começam a convergir. A possibilidade de se discutir o tema educação em saúde na escola mais de uma vez permitiu que novos caminhos se abrissem para a educação em saúde na escola.

\section{CONCLUSÃO}

É consenso que a escola representa um tempo-espaço propício para a educação em saúde e a promoção da saúde dos alunos. No entanto, as práticas educativas quando não são elaboradas de forma a considerar os educandos como sujeitos ativos no processo e as características e necessidades locais como inerentes a esse processo, corre-se o risco de serem superficiais e não atingirem o objetivo final que é a promoção da autonomia dos jovens frente às escolhas envolvidas no processo saúde e doença. Os professores são apontados como os principais mediadores para uma efetiva educação em saúde na escola e a capacitação para tal é citada por vários pesquisadores da área como indispensáveis para atingir esse objetivo.

O processo de construção colaborativa com os professores da rede básica de ensino de um curso de educação à distância sobre saúde na escola mostrou-se positivo 


\section{Ensino, Saúde e Ambiente - V9 (1), pp. 43-62, Abril, 2016.}

em vários aspectos. Os encontros para as discussões realizadas com os professores acabaram sendo também um momento de reflexão sobre os conceitos de saúde e de educação e da relação entre teoria e prática. As falas e expressões que inicialmente remetiam ao texto pronto da Organização Mundial da Saúde ("saúde como completo bem estar") ao longo do percurso foi se mostrando mais estruturado e real, como uma busca ativa da saúde ressaltando-se a importância de promover discussões críticas a respeito da relação saúde/doença quando se pensa em autonomia diante desses processos. Além disso, os professores chegaram à conclusão de que a busca ativa necessita de uma formação que estimule a participação social nos processos regulatórios da Saúde, uma formação política dos jovens para a cidadania. Desta forma, extrapolouse de uma definição estática para uma definição de saúde (e de educação em saúde) que busca complexificar as várias vertentes (ambientais, religiosas, físicas, mentais, psicológicas, políticas, entre outras) de forma crítica e atuante. A partir daí, definir os textos, as técnicas e atividades que abririam horizontes na discussão sobre educação em saúde na escola foi consequência deste processo de reflexão.

Contudo, as técnicas da construção colaborativa, enquanto pesquisa, aberta ao diálogo com os sujeitos pesquisados, mostrou um potencial pedagógico e de transformação, não somente dos sujeitos mas dos pesquisadores também. Desta forma, a pesquisa em educação em saúde significou o start para novas ações visando a promoção da saúde dos alunos e maiores discussões sobre saúde na escola. Além de culminar com a construção de um curso de Aperfeiçoamento em Educação em Saúde na Escola que ampliará ainda mais as discussões sobre o tema, aplicará práticas educativas em saúde na escola e contará com as trocas de experiências de professores de diversas áreas.

O Programa Nacional de Alimentação Escolar foi apontado como um caminho potencial para abordar os temas de saúde de maneira transdisciplinar e integrar os demais projetos vigentes na escola. Abordar a saúde a partir da alimentação, da produção consciente de alimentos de forma a não agredir o ambiente, com a utilização da horta agroecologia já existente neste espaço escolar, abriu para os professores a possibilidade de abordar temas como o consumismo, o imediatismo, formas de produção, agricultura familiar, transgenia, uso de agrotóxicos, obesidade, dislipidemias, hábitos alimentares, hábitos de vida, e uma infinidade de outras temas que a alimentação permite.

"Eu acho que esse nome (do curso), por mais que a princípio ele tenha uma cara, né: "Não, vamos falar só de alimentação", é... essa questão do PNAE, além dela estar presente na escola e representar o 
Ensino, Saúde e Ambiente - V9 (1), pp. 43-62, Abril, 2016.

fornecimento de alimentos, abre-se uma gama de possibilidades de discussão.... tá presente a questão do direito, entra na questão do hábito, né? (...) Muitas janelas se abrem para discutir saúde a partir da alimentação" REUNIÃO DE CONSTRUÇÃO DO CURSO DE EAD - ENCONTRO 2 PROFESSORA B.

\section{REFERENCIAS BIBLIOGRÁFICAS}

BELLONI, M.L. Educação a Distância. Autores Associados. 6 Ed. Campinas/SP, 2012.

BRASIL. Ministério da Educação. Secretaria de Educação Média e Tecnológica.

Parâmetros Curriculares Nacionais (Ensino Médio). Brasília: MEC, 2000.

CARTA DE OTTAWA. Primeira conferência internacional sobre promoção da saúde. Ottawa, novembro de 1986.

CASEMIRO, J.C.; FONSECA, A.B.C.; SECCO, F.V.M. Promover saúde na escola: reflexões a partir de uma revisão sobre saúde escolar na América Latina. Ciência e Saúde Coletiva, v: 19, n: 3. Rio de Janeiro, março, 2014.

COSTA, S.; GOMES, P.H.M.; ZANCUL, M.S. Educação em Saúde na escola na concepção de professores de Ciências e de Biologia. Encontro Nacional de Pesquisa em Educação em Ciências, Campinas, 2011, Anais...; Campinas/Sp; 2011.

DOWNIE, R. S; TANNAHILL, C.; TANNAHILL, A. Helth ptomotion: models and values. 2 ed. Oxford: OUP, 1996.

FERNANDES, M.H.; ROCHA, V.M.; SOUZA, D.B. A concepção sobre saúde do escolar entre professores do ensino fundamental. História, Ciências e Saúde - Manguinhos, Rio de Janeiro, 2005.

FOCESI, E. Educação em saúde na escola, o papel do professor. Revista Brasileira de Saúde Escolar, v. 1, n. 2, p. 4-8, abril, 1990.

FREIRE, P. Pedagogia da Autonomia: saberes necessários à prática educativa. Rio de Janeiro: Paz e Terra, 1996.

FREIRE, P. Pedagogia do Oprimido. 48 ed. Paz e Terra: Rio de Janeiro, 2005

GLANZ, K.; RIMER, B.K.; VISWANAT, K. Health Behavior and Health Education: Theory, Research, and Practice. Editora Jossey-Bass, 4TH EDITION, 2008.

GOFFMAN, E. Os quadros da Experiência Social. Uma perspectiva de análise. Editora Vozes, 2012.

GUSTAVO, L.S; GALIETA, T. A educação em saúde está contemplada na formação inicial de professores de ciências biológicas? Revista da SBEnBio, outubro de 2014. 
IERVOLINO, S.A.; PELICIONI, M.C.F. Capacitação de professores para a promoção e educação em saúde na escola: relato de uma experiência. Revista Brasileira de

Crescimento e Desenvolvimento Humano. 15 (2): 99-110; 2005.

IPPOLITO-SHEPHERD, J. A Promoção da Saúde no Âmbito escolar: A iniciativa Regional Escolas Promotoras da Saúde. In Caderno de Escolas Promotoras de Saúde. In Memórias III Reunión Latinoamericana de Escuelas Promotoras de la Salud. Quito: OPAS, p. 8$13,2002$.

MINISTÉRIO DA EDUCAÇÃO. Currículo Nacional do Ensino Básico: competências essenciais. Departamento de Ensino Básico. Lisboa, 2001.

MOTA, D.F.S. Trabalhar a educação para a saúde nas escolas: percepção de profissionais de saúde e de professores. Dissertação de mestrado em educação para a saúde. Universidade do Porto, Porto, 2011.

NONOSE, E.R.S.; BRAGA, T.M.S. Formação do professor para atuar com saúde/doença na escola. Anais EDUCERE, 2008. Disponível em http://www.pucpr.br/eventos/educere/educere2008/anais/pdf/407_455.pdf, em abril, 2015.

ORGANIZAÇÃO PAN-AMERICAN DE SAÚDE (OPAS/OMS). Escuelas promotoras de la salud: entornos saludables y mejor salud para las generaciones futuras. Washington, 1998.

PORTRONIERI, F.R.D.S.; FONSECA, A.B.C. A construção da imagem corporal entre jovens do ensino fundamental: a questão da identidade e da diferença e o papel do professor. Revista Ensino, Saúde e Ambiente, v. 5, n. 3, dez, 2012.

Reali, A.M.M.R.; Tancredi, R.M.S.P.; Mizukami, M.G.N. Programa de Mentoria Online: Espaço para o desenvolvimento profissional de professoras iniciantes e experientes.

Educação e Pesquisa, São Paulo, V. 34, N.1, P. 077-095, Jan./Abr. 2008.

RODRIGUES, V.; et al. Os professores e a educação/promoção para a saúde. Braga: Instituto de Estudos da Criança da Universidade do Minho, maio 2007. Disponível em: http://hdl.handle.net/1822/6694 em 15/01/2009 Acesso em 15 jan. 2009.

SABÓIA, V. M. Educação em Saúde: a arte de talhar de pedras. Niterói: Intertexto, 2003.

SCHALL, V.T.; STRUCHINER, M. Educação em saúde: novas perspectivas. Cad. Saúde Pública, Rio de Janeiro, v. 15, supl. 2, p. S4-S6, 1999.

SOUZA, F. V. F. R. Leitura de materiais educativos usados na educação em diabetes: uma análise por meio da semiótica social. Dissertação (Mestrado) - NUTES-UFRJ, 2009.

VENTURI, T. ; Hansen, K. S. ; PEDROSO, I. . Discutindo uma nova perspectiva para a Educação em Saúde: relato de uma experiência. In: Encontro Nacional de Ensino de Ciências da Saúde e do Ambiente, 2014, Niterói/RJ. Anais... Niterói/RJ, 2014. p. 1. 
Ensino, Saúde e Ambiente - V9 (1), pp. 43-62, Abril, 2016.

VENTURI, T. ; PEDROSO, I. ; MOHR, A. Educação em Saúde na Escola a partir de uma Perspectiva Pedagógica: discussões acerca da formação de professores. In: Encontro Regional Sul de Ensino de Biologia. XVI Semana Acadêmica de Ciências Biológicas: a docência em biologia: da formação inicial à formação continuada tecendo CTSA, 2013, Santo Ângelo/RS. Anais... Santo Ângelo/RS, 2013. 